\title{
Um outro Ernâni Braga: aspectos pessoais revelados em correspondências com Fernando Corrêa de Azevedo entre 1945-1948
}

\author{
Álvaro Carlini* \\ Universidade Federal do Paraná
}

\section{Resumo:}

Ernâni Braga (1888-1948) foi personalidade de destaque no cenário musical brasileiro da primeira metade do século XX. Além de sua participação como pianista na Semana de Arte Moderna realizada em São Paulo em 1922, Ernâni notabilizou-se por inúmeras atividades itinerantes que realizou como professor, agente cultural e regente coral, nos anos de 1930 até seu falecimento, em 1948. Entre 1945-1946. Curitiba, Paraná, organizou e regeu grupos corais para a recém-criada Sociedade de Cultura Artística Brasílio Itiberê (SCABI), atuando também como pianista solista e acompanhador, e como professor, ministrando cursos de especialização musical para docentes da rede estadual e municipal de ensino. Neste período, Ernâni Braga estabeleceu estreitos laços de amizade com Fernando Corrêa de Azevedo (19141975), presidente da $S C A B /$ e de outras entidades culturais do Paraná. Com ele, Ernâni Braga manteve naqueles anos uma série de correspondências de caráter pessoal, documentos que revelam aspectos de sua personalidade, de seus hábitos e manias, de sua visão bem-humorada da vida musical de seu tempo. Acredita-se que esses documentos, apesar de já editados na metade da década de 1960, permanecem desconhecidos da maioria dos musicólogos, pois foram publicados em anuário de circulação restrita, relacionado às atividades da Faculdade de Filosofia. Ciências e Letras da Universidade Católica do Paraná, em 1965, exatos 20 anos após o concerto de inauguração do $S C A B I$. O presente artigo tem como objetivo reapresentar à comunidade científica este material, realizando considerações sobre as atividades de Ernâni Braga e de Fernando Corrêa de Azevedo em Curitiba, mediadas através da SCABI.

Palavras-chave: Ernâni Braga (1888-1948); Fernando Corrêa de Azevedo (19131975); Sociedade de Cultura Artística Brasílio Itiberê (SCABI); Entidades civis vinculadas à música no Estado do Paraná, século XX

* Álvaro Carlini é docente adjunto vinculado ao Departamento de Artes da Universidade Federal do Paraná (DeArtes-UFPR), tendo como área de pesquisa a Musicologia Histórica, com ênfase em aspectos culturais e representações sociais civis no Brasil (sécs. XX-XXI). 


\section{Ernâni Braga em Curitiba pela SCABI em 1945: a amizade com Fernando Corrêa de Azevedo e o artigo do Humanitas, de 1965}

Um amigo verdadeiro e dedicado, que de amigo mil provas já tenha dado: um amigo que carinho e gentileza te dispense, na alegria e tristeza; um amigo que te queira e considere, quanto mais a sorte inimiga te fere; um amigo generoso, bom, leal, seja o dia de bonança ou de temporal; um amigo que te dê paz e conforto, como encontra um náufrago em seguro porto; um amigo que, do pão de cada dia, um pedaço te oferte, com fidalguia; um amigo cujo afeto não destroem, tempo e ausência que o sentimento corroem; um amigo que te abrace, emocionado, cada vez que voltas, e está a seu lado; um amigo assim, tão nobre na amizade, nesse mundo ingrato de hoje é coisa rara; é amigo do qual só se faz menção para honrá-lo, como de exceção: é amigo que te dá força e coragem para afrontar o que o mundo tem de selvagem; é amigo que o teu coração invade para enchê-lo de gratidão e saudade; é amigo que teu coração cultua porque sente que tem alma irmã da tua.

(Poesia de Ernâni Braga, de 1945, dedicada a Fernando Corrêa de Azevedo) ${ }^{1}$

Ernâni Braga apareceu pela primeira vez em Curitiba, Paraná, em 1945. Veio acompanhado da cantora Maria Kareska² para participar do concerto de inauguração da Sociedade de Cultura Artística Brasílio Itiberê, a $S C A B$ I, entidade civil sem fins lucrativos que se responsabilizou pela maioria das atividades musicais na capital paranaense até meados da década de 1970. O convite de então fora feito pelo presidente recém-empossado da SCABI, Fernando Corrêa de Azevedo:

\footnotetext{
${ }^{1}$ Apud Marisa Ferraro Sampaio, em Memória-Paraná (XXII): Fernando Corrêa de Azevedo (1913-1975). Uornal do Comércio, Curitiba, fev. 1989).

${ }^{2}$ Sobre Maria Kareska não foram localizadas informações mais precisas. Ressalta-se, porém. um dos trabalhos artísticos de Flávio de Carvalho (1899-1973), representante da vanguarda cultural paulistana das décadas de 1930-1950, intitulado Retrato da cantora Maria Kareska (óleo sobre tela, $110 \times 80 \mathrm{~cm}$ ), pintado em São Paulo, em 1950, o que sugere a presença da artista na capital paulistana naquele período. Disponivel em: http://www.escritoriodearte.com; e http://www.faap.br/museu.htm.
} 
Em janeiro de 1945, preparávamos o concerto inaugural da Sociedade de Cultura Artística Brasílio Itiberê, recém-fundada, quando surgiu em Curitiba Ernâni Braga, voltando ao Brasil depois de longa permanência na Argentina. Já o conhecia e de vista há muitos anos, mas foi só então que me foi dado travar amizade e estreitar relações com essa figura ímpar de músico e de boêmio, com essa inteligência privilegiada, com essa excelente cultura geral, com esse espírito curiosíssimo e cheio de ironia, com esse 'gentleman' despreocupado e alegre que foi Ernâni Braga. Ligou-nos então uma amizade íntima e uma simpatia recíproca, que nos acompanhou nos seus últimos anos de vida.

Por um cachê de $C r \$ 500$, acordamo-nos em que ele e Maria Kareska, que o acompanhava, participassem do concerto inaugural da $S C A B I$, responsabilizando-se pela terceira parte do programa. Ele tocou nessa ocasião o seu Tanguinho e a Embolada e acompanhou Maria Kareska em duas esplêndidas harmonizações suas: Engenho Novo e São João da-ra-rão. ${ }^{3}$ Essa foi a primeira de uma série de atividades que o ligaram a Curitiba por espaço de um ano, durante o qual ele organizou corais, um curso de Regência de Coros e Professores de Canto Orfeônico e perto de vinte concertos, educativos e públicos.

Cada aula do curso [...] era minuciosamente preparada por ele, esquematizada e depois mimeografada e distribuída aos alunos, que ficaram assim com um curso bastante completo, ordenado, bem estruturado, em esquemas claros e perfeitamente condensados, tudo desenhado com aquela letrinha regular que era o índice de uma personalidade definida e acentuadamente delineada.

Foram igualmente notáveis os conjuntos corais por ele ensaiados: universitários, normalistas, crianças de curso primário. A 7 de setembro de 1945, no Estádio Belfort Duarte, em Curitiba, regeu um coral de 3.000 crianças dos grupos escolares da Capital, com um sucesso acima de toda expectativa. [...]

Tenho vasta correspondência de Ernâni Braga, por onde se pode penetrar no âmago dessa personalidade sui generis, nesse misto de artista e de boêmio, de criador genial e de aventureiro, nesse sentimental irrefletido e inconseqüente, nessa inteligência de escol, servida por uma cultura sólida e sedimentada e por uma ironia fina e maliciosa. (1965, p. 41-55).

\footnotetext{
${ }^{3}$ Conforme se pode observar no fac-símile do programa inaugural da SCAB/ em 1945 (fig. 1), Maria Kareska interpretou também duas outras peças acompanhadas ao piano por Ernâni Braga: O rouxinol, de Alabieff e a ária Una voce poco fa, da ópera O barbeiro de Sevilha, de Rossini.
} 


\begin{tabular}{|c|}
\hline 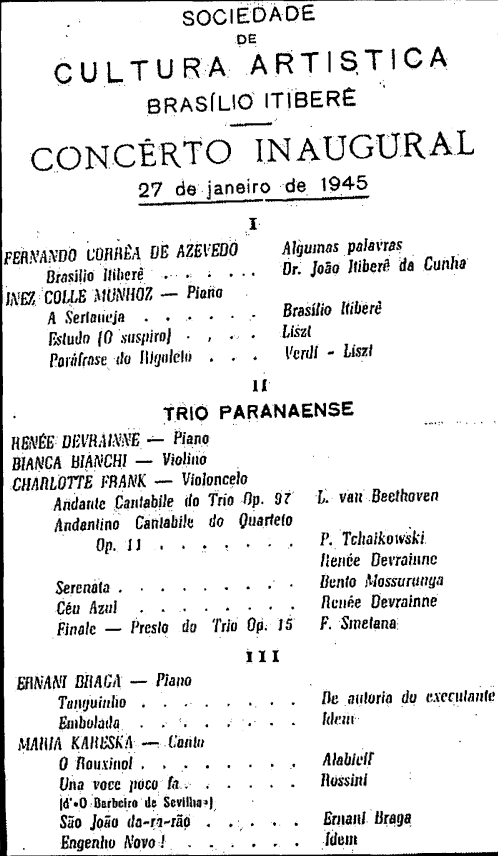 \\
\hline
\end{tabular}

Figura 1 Fac-símile de programa do concerto inaugural da Sociedade de Cultura Artística Brasílio Itiberê (SCABI), 27 de janeiro de 1945

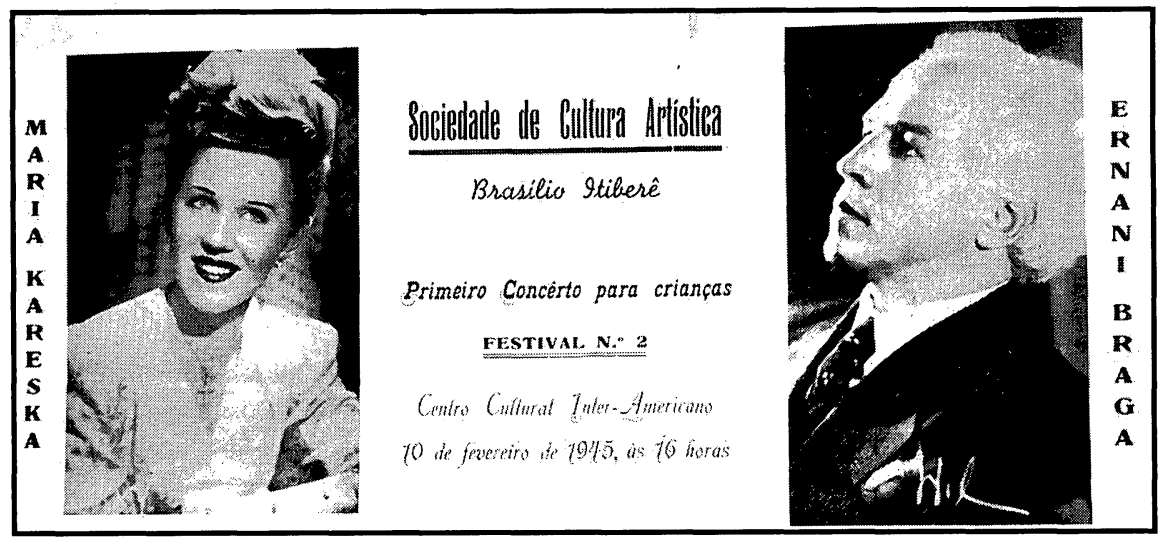

Figura 2 Fac-símile de programa de concerto da $S C A B /$ : primeiro concerto para crianças, Festival n.2 Centro Cultural Inter-Americano, Curitiba, 10 de fevereiro de 1945 
Fernando Corrêa de Azevedo editou em 1965, exatos 20 anos após o evento de inauguração da $S C A B I$, artigo com trechos das correspondências que manteve com Ernâni Braga entre 1945 até 1948, ano em que o maestro carioca faleceu, quando então residia, pela segunda vez, na cidade de São Paulo. O artigo, intitulado "O Ernâni Braga que eu conheci: aspectos sentimentais e humorísticos de uma grande e forte personalidade, através de sua correspondência", foi publicado em anuário das atividades desenvolvidas pela Faculdade de Filosofia, Ciências e Letras - o Humanitas (Figuras 3, 4 e 5) vinculada à Universidade Católica do Paraná, posteriormente, Pontifícia Universidade Católica do Paraná, PUC-PR. Nesta entidade, Fernando Corrêa de Azevedo manteve-se vinculado desde a sua fundação, em 1952, até 1971. quando retornou junto com a família para o Rio de Janeiro. Em 1963, ele passou a ocupar o posto de vice-reitor da Universidade Católica do Paraná, permanecendo no cargo até o seu retorno a capital carioca (cf. Ferraro, 1989).
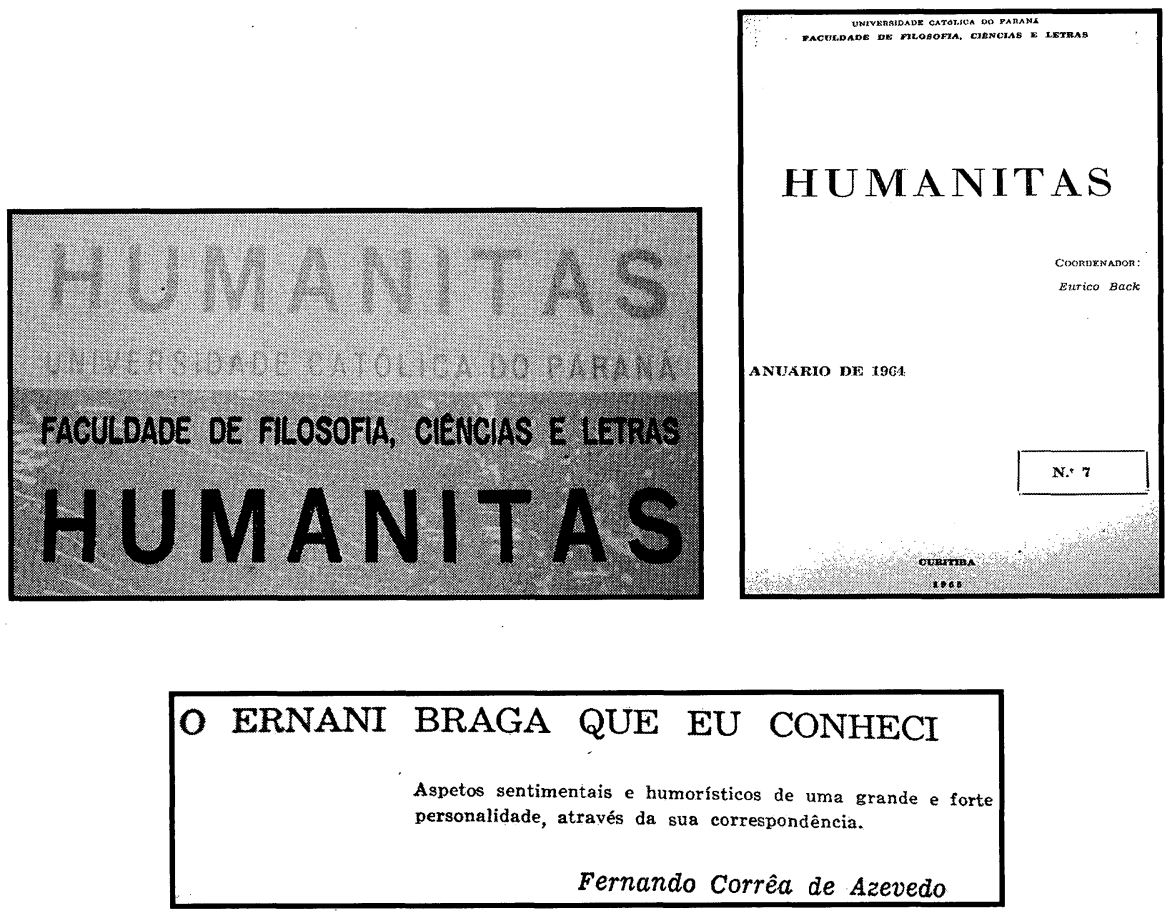

Figuras 3, 4 e 5 Fac-símiles do Humanitas, anuário de 1964 (1965) da Faculdade de 'Filosofia, Ciências e Letras da Universidade Católica do Paraná 
Apesar de publicado, este artigo de Fernando Corrêa de Azevedo não teve ampla divulgação, particularmente, entre pesquisadores de áreas da Musicologia, considerándo-se principalmente a circulação restrita e específica do Humanitas. Acredita-se que foi devido a essa característica que este texto não tenha recebido com o passar dos anos a devida valorização histórica, colaborando para a freqüente ausência de estudos acadêmicos posteriores que explorassem aspectos de ambas as personalidades, seja Ernâni Braga, seja Fernando Corrêa de Azevedo, pesquisando as suas atuações artísticas e culturais no Brasil e. em especial, no Estado do Paraná.

\section{Um pouco sobre Fernando Corrêa de Azevedo em Curitiba}

São inúmeras as atividades desenvolvidas por Fernando Corrêa de Azevedo (1913-1975) em Curitiba. Irmão mais novo do musicólogo Luiz Heitor Corrêa de Azevedo (1905-1992), como ele, nascido no Rio de Janeiro, RJ. Fernando estabeleceu-se na capital paranaense em 1937, após contrair matrimônio com a curitibana Yolanda Pontes, professora de língua inglesa no 140 Instituto de Educação do Estado do Paraná (Ferraro, 1989). ${ }^{4}$ A intensa contribuição de Fernando Corrêa de Azevedo para a educação e para as artes no Paraná está ainda por ser melhor pesquisada e compreendida, não sendo, no entanto, objeto específico de abordagem no presente artigo. Em texto redigido em 1989 para o Jornal do Comércio, de Curitiba, a jornalista Marisa Ferraro Sampaio comentou:

\footnotetext{
${ }^{4}$ Yolanda Pontes Corrêa de Azevedo reside atualmente na cidade do Rio de Janeiro. Em julho de 2008, concedeu entrevista em que recordou a estreita amizade entre Ernâni Braga e seu marido. Na oportunidade, salientou que as correspondências mantidas entre eles não foram preservadas e que os seus originais encontram-se desaparecidos.
} 
Fernando Corrêa de Azevedo deu ao Paraná contribuições de valor inestimável. Liderou com entusiasmo e persistência as principais iniciativas relacionadas com as artes e a cultura. Do imenso trabalho que realizou, a criação da Escola de Música e Belas Artes do Paraná [EMBAP] é o maior comprovante. Dotado de extraordinária capacidade administrativa, aliada à grande sensibilidade artística e musical, foi dela a mola propulsora, tornando-se figura insubstituível, o seu diretor perpétuo. Dirigindo-a durante 17 anos, de 1948 a 1965, criou verdadeiro celeiro de músicos e pintores. Homem de caráter firme, íntegro, dinâmico e culto, estruturou o então Departamento de Cultura da Secretaria de Educação e Cultura e assumiu a direção do mesmo nos anos de 1949, 1951 e 1952. [...] Lecionou em diversos colégios, institutos e faculdades da nossa capital. Incontáveis as atuaçōes que teve no setor cultural e artístico, a destacar: a fundação da Sociedade de Cultura Artística Brasílio Itiberê (SCABI), da qual foi presidente durante quase 30 anos, de 1944 a 1971; membro da Comissão Paranaense de Folclore, com várias e importantes pesquisas; membro do Conselho do Patrimônio Histórico, Artístico e Cultural do Paraná; secretário da Comissão Estadual de Música do IBECC; diretor da Juventude Musical Brasileira, setor do Paraná/Santa Catarina, a qual deu forte impulso.

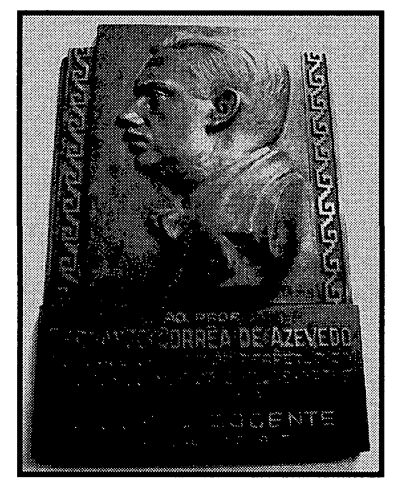

Figura 6 Placa localizada na Escola de Música e Belas Artes do Paraná (EMBAP), com os dizeres: "Ao prof. Fernando Corrêa de Azevedo fundador e diretor perpétuo da Escola de Música e Belas Artes do Paraná. O corpo docente. Curitiba, maio 1965".

O convite feito a Ernâni Braga, em 1945, para a participação no concerto inaugural da $S C A B /$ foi iniciativa de Fernando Corrêa de Azevedo, que contou com o apoio e incentivo dos demais responsáveis pela recém-criada entidade cultural paranaense. Considera-se aqui a possibilidade de o contato entre ambos ter sido significativamente facilitado pelas relações pessoais e profissionais comuns, já que tanto Ernâni Braga quanto Fernando Corrêa de Azevedo eram naturais do Rio de Janeiro, e ambos estavam residindo fora do domicílio de origem. 


\section{Um pouco sobre a vida itinerante de Ernâni Braga}

Ernâni Braga nasceu no Rio de Janeiro, RJ, em 1888. Estudou no Instituto Nacional de Música e, desde 1908, passou a integrar o corpo docente daquela Instituição. ${ }^{5}$ No entanto, o reconhecimento dos seus méritos musicais e a sua maior publicidade nos meios artísticos deu-se em São Paulo, com a participação na Semana de Arte Moderna de 1922, em que ele atuou no primeiro e no terceiro dia do evento realizado nos dias 13, 15 e 17 de fevereiro. No primeiro dia, interpretou obras de autores franceses na conferência do escritor Graça Aranha intitulada $A$ emoção estética da arte moderna. Foi devido a essa atuação que Ernâni Braga viu-se envolvido, involuntariamente, em polêmica com a pianista Guiomar Novaes, por ter executado obra de Francis Poulenc com referências satíricas à marcha fúnebre de Frédéric Chopin (cf. Wisnik, 1983, 77-78). Durante a Semana, Ernâni Braga notabilizou-se especialmente como intérprete da obra pianística de Heitor Villa-Lobos. A sua participação no evento teve influência de recomendação expressa de Villa-Lobos, que o considerava intérprete excelente de sua obra pianística. ${ }^{6}$

Após a Semana de 22, Ernâni Braga permaneceu na capital paulista,

142 residindo na cidade até fins da década de 1920. Estabelecido como concertista e professor de piano, teve a oportunidade de ministrar aulas para Camargo Guarnieri (1907-1993), somando-se ao maestro italiano Lamberto Baldi, a Antônio Leal de Sá Pereira e a Mário de Andrade na formação do compositor paulista. ${ }^{7}$ No entanto, apesar do reconhecimento público e de relativa

\footnotetext{
${ }^{5}$ ERNÂNI BRAGA, em Enciclopédia da Música Brasileira, 1977.

${ }^{6}$ Ernâni Braga teve intensa participação na Semana de Arte Moderna de 1922. Além das ilustrações musicais executadas durante a conferência de Graça Aranha, apresentou-se com destaque como pianista solista interpretando obras de Heitor Villa-Lobos. Ainda no primeiro dia, após a conferência de Graça Aranha, Ernâni Braga apresentou em solo a Valsa mistica (1917) e Rodante (1919), ambas da série Simples coletânea, e $A$ fiandeira (1921); no último dia, novamente em solo, executou Camponesa cantadeira (1916), da Suíte Floral; Num berço encantado (1919), da série Simples coletânea; e Dança infernal (1920). Ainda no último dia da Semana, Ernâni Braga tocou celesta no Quarteto Simbólico - impressões da vida mundana, de 1921, escrito para flauta transversal, saxofone, celesta e harpa, com vozes femininas em coro oculto (Cf. WISNIK, 1983. p. 67-79).
}

${ }^{7}$ ERNÂNI BRAGA, em Enciclopédia da Música Brasileira, 1977. 
estabilidade financeira, Ernâni Braga não se adaptou ao ambiente profissional de São Paulo, marcado pela influência italiana atuante na principal instituição de ensino musical da cidade, o Conservatório Dramático e Musical, e pelas difíceis relações entre cariocas e paulistas naquele período, conforme relatou em correspondência com Luciano Gallet, datada de 23 de agosto de 1923, a quem se dispôs a ajudar amigo comum:

Gallet, [...] Digo-te fora da minha imensa modéstia, que é nula a minha influência no ambiente Paulista. Portanto, disponha o Vilmar do meu contingente pessoal que, apesar de nulo também, tem a vantagem inestimável de ser carioca. Reparaste no maiúsculo do Paulista e na insignicância [sic] do carioca? Nasceramme os dois, assim, espontaneamente, do bico da pena. De onde posso afirmar que o parto foi feliz, pois os indivíduos dados à luz, (mesmo fora da Estação da dita) trouxeram as suas características e prerrogativas desde o... bico materno. Agradeço-te os bons votos com que tens acompanhado a minha trajetória artística, e se, de fato, não a perdeste de vista, posso assegurar ao mundo que tens bom olho ou, quando menos, um ótimo coração. Até há pouco, andei por aqui rolando, qual cometa vagabundo, sem papel definido na organizaçăo do sistema planetário-musical-ítalo-Paulista. Agora sinto que estou começando a evoluir... Noto um certo orgulho cósmico, que algumas moléculas e não poucos átomos se vão, pouco a pouco, desagregando daqueles astros luminosos, para aderirem à cauda do cometa. Que não me atrapalhem a marcha astronômica! Da tua atividade e dos teus sucessos como compositor, como virtuose, como regente e como professor, tenho sabido e, sempre, com maior prazer. Dou-te os meus calorosos parabéns pela tenacidade do esforço e pela felicidade da realização. Dáme, quando puderes, notícias tuas. Aqui estarei para tudo o que julgares ao meu alcance e que te possa servir. Um afetuoso abraço do Ernâni. ${ }^{8}$

Apesar de esperançoso, conforme pôde ser observado nesta carta a Luciano Gallet, a situação profissional de Ernâni Braga em São Paulo não melhorou com o passar do tempo. Assim, após sete anos de moradia na capital paulistana, em 1928, Ernâni Braga decidiu iniciar viagem que perdurou um ano. na qual percorreu a maioria das capitais do Norte e Nordeste do Brasil. De Salvador a Manaus, realizou 19 concertos.

Em 1929. Ernâni Braga optou por fixar moradia no Estado de Pernambuco, passando então a residir em sua capital, Recife. A sua estadia por lá, de cerca de 10 anos, foi bastante produtiva, resultando, dentre tantas outras iniciativas, na criação do

\footnotetext{
${ }^{8}$ Dolores Castorino Brandão e M ${ }^{a}$ Luisa Nery Carvalho, Biblioteca Alberto Nepomuceno da Escola de Música da UFR/. Disponível em: http://www.sibi.ufrj.br/bibmusica.pdf. Acesso em: maio 2008.
} 
Conservatório Pernambucano de Música, instituição que continua ativa até os dias atuais. Sua permanência e contribuição artística, pedagógica e cultural naquele Estado foi objeto de estudo da pesquisadora Gisete de Aguiar Coelho Pereira, publicado em 1986, pela Secretaria de Educação de Pernambuco. Na presente pesquisa este foi o único trabalho localizado que realiza de maneira específica estudo biográfico sobre Ernâni Braga, privilegiando, particularmente, as diversas atividades do maestro em Pernambuco. Segundo Roberto Benjamin, diretor do Departamento de Cultura e responsável pela apresentação do livro:

Entre as múltiplas atividades que Ernâni Braga exerceu em Pernambuco está a direção do Serviço de Música e Canto Orfeônico, célula inicial do atual Departamento de Cultura da Secretaria de Educação, primeiro organismo do Governo de Pernambuco para coordénação das atividades cultúrais. Foi ele o primeiro diretor e em decorrência deste fato sentimos a necessidade de levantar a sua biografia e de redescobrir o seu pensamento, guardado disperso em velhos jornais. Em conseqüência do descaso com os documentos públicos, tão comum entre nós e particularmente pela intencional destruição dos arquivos deste órgão, quase nada foi levantado sobre a sua atuação.

A importância de Ernâni Braga na história da música brasileira e em particular a sua contribuição para a vida cultural de Pernambuco transcende a atividade desenvolvida naquele posto. Além de inspirado compositor que aderiu as diretrizes nacionalistas do Modernismo de [19]22, ele próprio participante da Semana como concertista, Ernâni Braga foi o impulsionador da modernidade na área da música em Pernambuco. [...] Ele dominou os meios musicais na décadas de [19]20 e [19]30 com marcante atuação como compositor, concertista educador, regente de corais, crítico de música e animador cultural. Nenhuma atividade musical ocorreu no período, sem que Ernâni Braga, de alguma maneira, estivesse envolvido. Por tudo isto, ainda que lamentando a lacuna quanto a sua atividade na administração de atividades culturais, estamos seguros de que o resgate da memória de Ernâni Braga não é apenas um ato de justiça que se faz a quem tanto se dedicou a Pernambuco, mas uma contribuição relevante ao conhecimento da história da cultura e um exemplo para as novas gerações. (Pereira, 1986, p. 7).

$\mathrm{Na}$ introdução do estudo, redigida pela pesquisadora Gisete de Aguiar Coelho Pereira, intitulada Quase uma autobiografia, há um breve panorama das atividades, da personalidade e de outros aspectos da estadia de Ernâni Braga em Pernambuco: 
O nome de Ernâni Braga destaca-se entre os que se empenharam na criação de uma linguagem musical brasileira. Sua forte personalidade, sua energia ilimitada e o seu grande entusiasmo cativaram todos. Foi na música um compositor romântico, um intérprete brilhante, um eminente mestre. Sua habilidade pessoal levou-o a ocupar posição de destaque no cenário social e artístico de Pernambuco, em uma época de transformações profundas durante uma década, recebeu críticas e teve admiradores, mas foi sempre respeitado por todos. Seu nome está intimamente ligado ao Teatro Santa Isabel, ao jornal A Província, ao Conservatório Pernambucano de Música, à antiga Escola Normal Oficial, às sociedade musicais e ao ensino do nosso Estado.

É comum lembrá-lo apenas como uma passagem efêmera e superficial na vida musical pernambucana, ou como mais um simples professor de piano vindo de fora ao lado de tantos outros. Houve quem o considerasse um intruso. A verdade, porém, é que Ernâni Braga excedia na capacidade de explorar todas as potencialidades de quem luta em favor de realizações a longo prazo, com resultados duradouros. Não foram idéias originais, apenas concretizadas. Tinha capacidade de trabalho duro, falar em público, transmitir conhecimentos, suas experiências, sua técnica aos discípulos e também cuidar dos mínimos detalhes na organização de concertos e audições. (1986, p. 9).

\section{A colaboração artística e pedagógica de Ernâni Braga em Pernambuco foi} notável. Durante cerca de 10 anos, suas atividades transformaram a realidade cultural local. No entanto, em 1937, Ernâni Braga decidiu deixar Recife. Segundo Gisete de Aguiar Coelho Pereira, esta decisão deveu-se sobretudo às dificuldades enfrentadas pelo maestro para a obtenção de reconhecimento oficial do Conservatório Pernambucano de Música junto às autoridades. Tal processo foi ainda mais complicado levando-se em consideração a nova política decretada a partir do Estado Novo de Getúlio Vargas. O Interventor nomeado para Pernambuco, Agamenon Magalhães, de maneira algo ríspida, dispensou o trabalho de Ernâni Braga naquele Estado:

O entusiasmo pelo Conservatório, na burguesia do Recife, havia passado. [...] Os seus amigos que ocuparam cargos importantes no Governo anterior caíram no ostracismo. Alguns haviam até sido convidados a deixar o Recife, logo após o golpe de novembro de 1937. Ernâni Braga com seu temperamento irrequieto havia entrado em conflito com diversas personalidades do mundo musical e polemizado com a maioria dos críticos musicais do Recife. [...] O novo Governo o dispensou do cargo de confiança que ocupava no Serviço de Música e Canto Orfeônico. A situação financeíra do Conservatório começou a deteriorar-se. Ernâni Braga resolveu pedir uma audiência com o Interventor, para situar a posição do Governo em relação ao Conservatório. [...] Admitido ao gabinete do Interventor, este o recebeu 
de pé. Agamenon Magalhães não estava disposto a muitas conversas. Julgando-se indispensável ao trabalho de educação musical do Recife, e irritado com a frieza do interlocutor, ousou a ameaçar o interventor todo poderoso, com a sua retirada, para atender propostas de trabalho mais compensadoras, fora de Pernambuco. Agamenon Magalhães respondeu-lhe que se o maestro não tinha compromissos de raízes pernambucanas deveria aceitar as ofertas de melhores vantagens e ir embora. Não faria falta. O curto diálogo estava encerrado e consumado o desencontro. Restava a Ernâni Braga, ferido em seus brios, abandonar a sua obra e partir em busca de novas oportunidades. Somente depois de consumado o seu afastamento que o Conservatório obteve o apoio governamental. (Pereira, 1986, p. 62).

Com seu afastamento de Pernambuco, em 1937, iniciou-se nova etapa de vida itinerante para Ernâni Braga. Novamente, durante dois anos consecutivos, entre 1938-1939, ele viajou pelo País, sem estabelecer residência fixa, apresentando-se em concertos e ministrando cursos de canto e de regência coral por diversos Estados brasileiros, entre eles, Pará, Maranhão, Espírito Santo, Santa Catarina e Rio Grande do Sul.

Em agosto de 1940. Ernâni Braga foi contratado pela Prefeitura de Porto Alegre, Rio Grande do Sul, para reger um coro de 5.000 vozes, integrando as comemorações do bi-centenário de fundação da cidade, patrocinadas pela Secretaria de Educação e pela Prefeitura. No primeiro semestre de 1941, realizou excursão artística e pedagógica pelo interior do Rio Grande do Sul, sempre se apresentando em recitais por várias cidades, além de ministrar cursos de canto e de regência coral. Durante sua permanência naquele Estado, ainda em 1940, teve a oportunidade de publicar coletânea de músicas regionais harmonizadas para canto e piano e para coro a capella (ver Figura 7).

Em 1942, mudou-se para a Argentina, estabelecendo-se em sua capital, Buenos Aires. No mesmo ano, assinou contrato para dirigir a parte musical do programa radiofônico Hora do Brasil [sic], levado ao ar duas vezes por semana naquele país. Ernâni Braga residiu na capital argentina até 1944, apresentando-se 
várias vezes em concertos de piano, executando peças do repertório brasileiro, incluindo as suas próprias composições (Pereira, p. 76). ${ }^{9}$

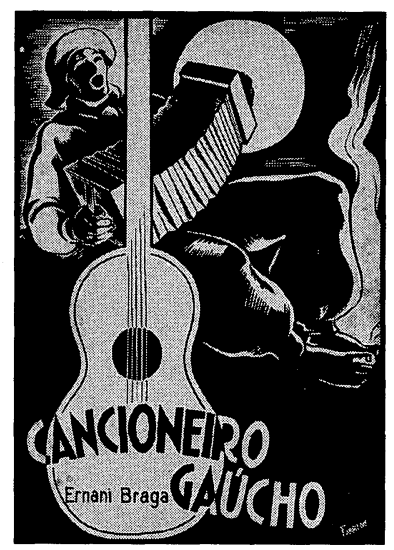

Figura 7 Fac-símile da capa de Cancioneiro Gaúcho, de Ernâni Braga (1940) ${ }^{10}$

Em 1942, mudou-se para a Argentina, estabelecendo-se em sua capital, Buenos Aires. No mesmo ano, assinou contrato para dirigir a parte musical do programa radiofônico Hora do Brasil [sic], levado ao ar duas vezes por semana naquele país. Ernâni Braga residiu na capital argentina até 1944, apresentando-se várias vezes em concertos de piano, executando peças do repertório brasileiro, incluindo as suas próprias composições (Pereira, p. 76). ${ }^{11}$

Em 1945, Ernâni Braga acompanhado da cantora Maria Kareska, veio a Curitiba a convite de Fernando Corrêa de Azevedo para participar do concerto de inauguração da Sociedade de Cultura Artística Brasílio Itiberê, a SCABI. Como visto anteriormente, sua permanência na capital paranaense estendeu-se por

\footnotetext{
${ }^{9}$ Além da Argentina (em Buenos Aires), Ernâni Braga residiu durante cerca de seis meses em Montevidéu, no Uruguai. Não foi, no entanto, localizada informação mais específica sobre as suas atividades naquele país.

${ }^{10}$ Ernâni Braga, Cancioneiro Gaúcho [Porto Alegre (RS): Livraria Globo, 1940]. Capa de Fahrion. Edição comemorativa. Conteúdo: Músicas para canto e piano e coro a capella. 11 Partituras (Prenda Minha; Tirana, Tira-Tirana; Meu Boi-Barroso; Trovas Saudosas; Chimarrita; Saudades do Gaúcho; Galinha Morta; Toada; Caranguejo; Velha Gaita).

${ }^{11}$ Além da Argentina (em Buenos Aires). Ernâni Braga residiu durante cerca de seis meses em Montevidéu, no Uruguai. Não foi, no entanto, localizada informação mais específica sobre as suas atividades naquele país.
} 
cerca de um ano, período no qual ministrou curso de canto e regência coral para professores da rede estadual paranaense, além de realizar concertos e palestras pelo interior do Paraná. Em fins de 1946, Ernâni Braga transferiu-se, por mais uma oportunidade, para São Paulo. De 1947, morando definitivamente na capital paulista, até 1948, ano em que faleceu. Ernâni Braga manteve contato estreito, através de correspondências, com Fernando Corrêa de Azevedo, em Curitiba.

\section{Outros trechos das correspondências de Ernâni Braga para Fernando Corrêa de Azevedo, entre 1945-1948}

No artigo de Fernando Corrêa de Azevedo, publicado em 1965 pela revista Humanitas, da então Universidade Católica do Paraná, foram apresentados cerca de 20 excertos das correspondências por ele recebidas de Ernâni Braga, no período de 1945-1948. Neste texto, Fernando Corrêa de Azevedo procurou estabelecer aspectos e características marcantes do amigo, na tentativa de melhor compreender a personalidade de Ernâni Braga. A amizade estabelecida entre ambos a partir do concerto de inauguração da $S C A B I$, em 1945, possibilitou uma avaliação bem peculiar do maestro carioca:

Mas era incorrigível o Ernâni Braga. Proibido de tomar vinho, jamais o vi almoçar ou jantar sem o seu cabernet, a sua garrafa de merlot, às vezes mesmo o seu Grandjó ou Casa da Calçada, num completo desprezo pelas prescrições médicas e pelo seu fígado doente, que o crucificava por vezes na maior das amarguras, deixando-o dias e dias de olho amarelo e faces cavernosas.

Para ele não havia maior prazer que uma roda de amigos, uma reunião íntima, uma boa mesa, um bom vinho e uma boa música. Com que alegria quase infantil ele freqüentava a casa hospitaleira de D. Saza Lattes, ${ }^{12}$ em noitadas memoráveis de um alegre e doce convívio. Lá era o ponto de reunião obrigatório, quase todas as noites. Sempre a mesma roda, sempre os mesmos amigos. Música, uma mesinha de pocker, uma adega generosa e sempre franca. Ele se foi e, logo depois dele, essa criatura extraordinária que foi D. Saza Lattes, essa anfitriã que ficará nos anais de Curitiba, pela fidalguia e pela hospitalidade amiga que oferecia a todos os artistas. Sua casa era a casa dos artistas. Mais do que qualquer outro. Ernâni Braga sentiu o calor desse acolhimento.

\footnotetext{
${ }^{12}$ Sobre Saza Lattes, veja Tablóide digital, em http://www.millarch.org/. Acesso em: dez. 2008.
} 
Inconseqüente por temperamento, malgrado aquela esplêndida cabeleira branca esvoaçante, de que ele, aliás, muito se orgulhava, ficava por vezes completamente sem dinheiro, para as menores despesas. Também não tinha, nessa época, nenhum ganho certo. Vivia de um ou outro concerto que arranjava; uma audição de rádio, sem nada que lhe garantisse o dia de amanhã. O futuro não o preocupava. Era um autêntico, um legítimo boêmio de cabelos brancos, na mais completa acepção do termo. (Azevedo, 1965, p. 42-43).

Como uma das carácterísticas mais marcantes da figura de Ernâni Braga,

Fernando Corrêa de Azevedo indicou o senso de humor:

Mas há outros [aspectos da personalidade de Ernâni Braga] que merecem igualmente a nossa atenção. $E$, entre eles, o sense of humor. Lembro-me de uma noite, num hotel de interior, em que ficamos até alta- madrugada, fechados num quarto, fazendo jogos de salão. Éramos quatro apenas. Disparates, provérbios, advérbios, retrato, amigo ou amiga, temas, etc., etc. A noite foi divertidíssima. As risadas, estrondosas, perturbaram o sono pacato dos hóspedes. Um advérbio insólito luziu na cabeça de $X^{13}$, pouco afeita ainda aos falares portugueses: galinhosamente. Ernâni Braga não resistiu. Esqueceu as conveniências, o lugar e a hora, e riu a bandeiras despregadas... Foi uma risada escandalosa, que ecoou pelos corredores soturnos daquele hotel numa madrugada já bem avançada. De manhã, acordei com um ligeiro ruído de papel embaixo da porta do meu quarto. Era um recado que ali estava sendo posto cautelosamente. Dizia: Salve. Amice! Fazendo votos para que Morfeu vos haja embalado em suas asas, (tinha asas o bicho. ou estou confundindo com morcego?), venho pedir-vos galinhosamente uma lâmina ad faciendam barbam (!!!) porque a minha, (última e decrépita), nem para escanhoar um bode velho, bem anestesiado. presta. Pede favorável deferimento. Um dos desordeiros desta noite de memorável farra. Maestro Ernâni Braga. (p. 44-45).

Além do senso de humor, Fernando Corrêa de Azevedo indicou o desapego ao dinheiro como um outro traço característico da personalidade de Ernâni Braga:

${ }^{13}$ Fernando Corrêa de Azevedo identificou apenas como "X" a pessoa que acompanhou Ernâni Braga durante a sua estadia no Paraná e nas viagens que ele realizou pelo interior do Estado. Trata-se, provavelmente, da cantora Maria Kareska. Ressalta-se que não é minha intenção desatender a precaução e cuidado de Fernando Corrêa de Azevedo com relação ao anonimato desta personalidade. No entanto, levou-se em consideração o caráter acadêmico e científico do presente artigo e o longo tempo transcorrido dos eventos mencionados por Fernando Corrêa de Azevedo e os dias atuais. 
O desapego ao dinheiro me parece ter sido outro traço marcante do seu modo de ser. Devendo ele realizar, a $1^{\circ}$ de maio, um concerto para operários, patrocinado pela Delegacia Regional do Trabalho, e sendo a verba posta à disposição por aquele órgão assaz pequena, fi-lo sentir, ao que me retrucou: Quanto ao cachê, não perca o sono, meu querido amigo. Nem só de pão vive o homem, mas também do prazer de conviver com os amigos e da glória de realizar alguma coisa pela arte, com devoção, com sinceridade, com entusiasmo. (Que bonito. hein?). O parênteses é dele. (p. 45).

Fernando Corrêa de Azevedo destacou também, em seu artigo de 1965 , o espírito crítico e algo irônico do maestro carioca. Como exemplificação, apresentou outros dois trechos das correspondências mantidas entre eles. No primeiro, destaca a sua ligação afetiva com a cantora lírica Julieta Teles de Menezes, de Pernambuco, que manteve contato com Ernâni após seu afastamento do Estado, em 1937.

A crítica e a ironia são igualmente elementos inseparáveis daquele espírito mordaz e observador:

Chegamos muito bem. O nosso companheiro de itinerância revelou-se o tipo demagogo barato. Viajou o tempo todo apregoando os seus princípios aliás muito novos, como o são geralmente os princípios dos que ainda não deram começo à digestão do que leram sobre socialismo, marxismo, comunismo e outros perigosos ismos, aos quais tomei em respeito, desde que a minha querida amiga Julieta Teles de Menezes descobriu o atavismo de um Plínio em Ribeirão Preto [SP]. Chegamos aqui literal e orelhamente ismados. Eu, mais que a nossa inefável $X$, que se deslumbrou com a verborrágica ismorréia do capitalista. Eu vinha sozinho ao lado do chofer. Quando começou a arenga ismática, começou também a invadir-me uma leve sonolência, que me levaria ao letargo mais profundo, se $X$ e o arengador não me despertassem para responder, quer eu quisesse ou não, às interpelações que, em certas fases da loqüela, me eram atiradas pelas costas. Eu tinha de me torcer para trás e dar meu beneplácito a todo aquele acaciano acervo de burrismos. Fomos assim até findar a hora segunda do nosso automobilismo. Nesta altura, (digo bem porque estávamos ainda na serra), fomos tomar um cafezinho.

Foi então que um mosquito olhou indiscretamente para as perninhas de $X$, e ainda achou que não havia grande mal (muito pelo contrário!) em aplicar-lhes algumas sucções. E aplicou-as! X estrilou, o que era muito do seu direito (jus estrilandi) e se coçou, o que era muito natural. A toda ação corresponde uma reação. Aí revelou-se não mais o ânimo demagógico, mas a alma compassiva de Y. - Um cálice de cachaça!, bradou. E o cálice apareceu, entre dedos rudes e trêmulos do barman, contando no seu pequenino bojo o líquido salvador. Como fazer-se a aplicação? X exibiu um minúsculo pañuelo [sic], que logo foi embebido, saturado da preciosa pinga. Quem faria a aplicação? Eu mesma, sugeriu a vítima, que ainda se achava bastante forte para a 
autocura. Permita-me que a ajude, implorava o médico, pressuroso em corrigir galinhosamente o sanguessuguismo do mosquito. Foi quando a vítima encontrou argumento que lhe daria a razão de se autofriccionar: Que[m] diria...?!... Daí em diante pôde friccionar-se quando e como quis, livre das caritativas insinuações do meigo $Y$. Quando fomos retornar ao automóvel, já encontrei a vítima do mosquito e da quase esfregação... sentada no meu lugar, ao lado do cinesíforo [sic]. (p. 45-46). ${ }^{14}$

E o outro trecho:

Ontem tivemos como nossa convidada, ao jantar, dona XX. A conversação com dona XX é uma arte assaz difícil. Todos os temas que propus (ela não propôs nenhum!), e que andavam pelos cinquenta, aproximadamente, em três horas de visita, foram caindo de maduros, um após outro, com apenas alguns monossílabos de desenvolvimento, intercalados de longos silêncios, ou de reticências angustiosas. De vez em quando, o sublinhado de uma risadinha, curta, indecifrável, extemporânea, paradoxal, que é uma das características de XX. Uma risadinha mais para dentro do que para fora, soturna, mais gargarejada, como a expressão gutural de um peru cansado, desiludido, que não se animasse mais a soltar o seu grou-grou com entusiasmo e convicção, deixando-o, ao invés, ressoar surdamente entre o bico e a garganta. Um dia ainda hei de estilizar esse ruído, empregando-o como efeito orfeônico, em alguma canção triste, sombria, lúgubre... por exemplo, A agonia do corvo. Lamentei, conversando com XX, não ter conservado na memória algumas das tiradas do homem dos ismos, para preencher com elas as intermitentes e freqüentíssimas pausas, os sonolentos vácuos que se produziam. Aliás, creio que de nada teria valido esse recurso também. Porque depois de cada risadinha, dona XX submergia em profunda abstração, que não a tolhia somente de falar, mas também de ouvir. A princípio eu procurava, com os meus apelos insistentes, exumá-la daquelas profundezas. Por fim, cansei-me, e transferi a $X$ a função de escafandro. E posso, em seu louvor, afirmar que consegui, mais uma vez, estabelecer uma relativa continuidade na conversação, graças aos temas novos que apresentava: criação de gansos, patos, marrecos; trabalhos de tricô; acessos de urticária, etc. Confesso que nesses efêmeros momentos, tive ganas de recompensar a minha gentil companheira de infortúnio. Mas a única maneira que me ocorria era dar-lhe uma esfregaçãozinha de cachaça na perna... e o momento não me parecia bastante adequado. (p. $46-47) .{ }^{15}$

Foi, provavelmente, devido ao seu estilo de vida, definido como sendo o de "um autêntico, um legítimo boêmio de cabelos brancos, na mais completa acepção do termo", conforme avaliou Fernando Corrêa de Azevedo (1.965), que

\footnotetext{
${ }^{14}$ Não foi possivel identificar as personagens $X$ e $Y$.

${ }^{15}$ Não foi possível identificar a personagem XX.
} 
Ernâni Braga enfrentou problemas hepáticos com relativa freqüência. De maneira sistemática, este aspecto de sua saúde foi também uma característica marcante da sua existência. Ainda de acordo com o texto de Fernando Corrêa de Azevedo:

Jamais Ernâni Braga se quis submeter a um tratamento sério ou ao menos à dieta, abstendo-se de álcool e de certos alimentos que the eram prejudiciais. Nunca deu ao seu mal hepático a atenção que ele requeria, o que acabou vitimando-o irremediavelmente. (p. 47, 50).

No entanto, apesar da gravidade do problema, Ernâni Braga o enfrentava jocosamente:

A crise de fígado me assustou apenas relativamente, pois eu sabia que, em aqui chegando, a Olina ${ }^{16}$ - essência da vida - me restituiria à luminosa juventude que enfrenta, impávida e vitoriosa, os Granjós do casal Lattes e as viúvas Clicquots do Martins Gomes. E assim foi. Cheguei, tomei a Olina e venci as caretas do fígado.

Fernando Corrêa de Azevedo relembrou no artigo do Humanitas de 1965 fato ocorrido momentos após a realização do concerto de inauguração da $S C A B l$, em 1945, relacionado ao precário estado de saúde de Ernâni Braga naquela 152 ocasião, motivado pelo seu fígado:

O enorme esforço desse empreendimento sobre o seu organismo já combalido pela doença que o havia de vitimar, provocou uma reação quase imediata. As últimas músicas já ele as regeu sob dores atrozes de uma cólica de fígado, que o levou do Estádio [Belfort Duarte, de Curitiba.] diretamente para a cama e os cuidados médicos.

Foi, de fato, devido a complicações com seu fígado que Ernâni Braga veio a falecer em São Paulo, em 16 de setembro de 1948. O jornal Gazeta do Povo, de Curitiba, noticiou seu sepultamento, no dia seguinte, na capital paulista:

\footnotetext{
${ }^{16}$ Nome de medicamento composto por ervas medicinais, introduzido no Brasil, em 1916. por imigrantes alemães, bastante utilizado na Região Sul do Brasil. Disponível em: http://www.olina.com.br/hist.htm. Acesso em: jan. 2009.
} 
Saindo do Teatro Municipal, onde esteve em câmara ardente durante o dia, foi sepultado ontem, às 17h, o professor Ernâni Braga. Ao sepultamento, no cemitério São Paulo, realizado às expensas do Estado, compareceu grande número de seus amigos e admiradores. O governador Ademar de Barros fez-se representar pelo capitão Alfredo Condeixas Filho. Ao ser baixada a urna, falou o professor Paulo Gomes Cardim, antigo aluno do compositor Ernâni Braga, ressaltando a sua figura e as suas realizações. ${ }^{17}$

Os dois últimos anos da vida de Ernâni Braga foram complicados em diversos aspectos, seja no setor financeiro, seja com a já debilitada saúde. Assim Fernando Corrêa de Azevedo comentou o assunto em seu artigo (Humanitas, 1965), apresentando em seguida, mais um trecho de carta recebida de Ernâni Braga:

Foram bem negros os últimos tempos de vida de Ernâni Braga em São Paulo. Premido pela necessidade, recorreu a amigos da Sul América, ${ }^{18}$ que o empregaram como agente de seguros. Mas ele só teria as porcentagens dos seguros que fizesse... Creio que nunca conseguiu fazer nenhum. Mesmo porque, ficava na sua mesa, na Sul América, a espera que os candidatos aparecessem. Vivia nessa época em São Paulo, numa casinha de subúrbio, distante, sem o menor conforto. As agruras dessa situação não conseguem Ihe abater o bom humor:

Cheguei de Campinas e encontrei várias situações encrencadas: a casa às escuras; o motor da bomba elétrica, queimado; um cachorro de estimação, raptado. Com cinco eletricistas, cada qual mais patife [que o outro], subindo ou descendo, ou mais cronologicamente, descendo e subindo pela escuridão dos 20 metros de fundura do poço. O motor continua paralítico. Isso vem durando a 20 dias: vivo sem uma gotinha de d'água nas torneiras. Você já experimentou as delícias de lavar o nariz, de manhã. com uma canequinha d'água? E a tomar banho por prestações, limpando hoje uma peça anatômica, amanhã outra? Francamente! A vida é um sonho. E os pesadelos... são a vida. Você já viu filosofia mais barata e reles? (p. 54).

De acordo com o livro de Gisete de Aguiar Coelho Pereira, mencionado anteriormente, também o Camargo Guarnieri, ex-aluno de Ernâni Braga, que então ocupava cargo de alguma influência política na

\footnotetext{
17 "A morte de Ernâni Braga, sentidas manifestações de pezar, pelo desaparecimento do consagrado maestro" [Gazeta do Povo, Curitiba , 19 set. 1948]. Este artigo da imprensa curitibana, sem identificação de autor, destacou o comparecimento ao sepultamento do maestro Ernâni Braga de algumas personalidades do mundo musical de São Paulo, como o pianista Sousa Lima, o professor Samuel Arcanjo, o compositor Camargo Guarnieri, entre outros.

${ }^{18}$ Empresa de seguros cuja razão social completa é Sul América Companhia Nacional de Seguros de Vida. Veja: http://portal.sulamericaseguros.com.br/data/pages.htm.
} 
administração paulistana, procurou auxiliar o maestro carioca em sua nova estadia por São Paulo. Valendo-se de sua posição, o compositor Camargo Guarnieri facilitou o processo burocrático para que Ernâni Braga conseguisse exercer atividade remunerada como professor de canto orfeônico em escola pública de São Paulo:

O maestro Camargo Guarnieri encontrava-se no gabinete de trabalho no Serviço de Música, que coordenava as atividades de música na escola pública paulistana, quando the anunciaram a presença de Ernâni Braga. Alquebrado, com os cabelos completamente brancos, olhos opilados, Ernâni Braga era o espectro do primeiro professor de piano que Guarnieri tomara, na capital paulista, anos atrás. Havia retornado a São Paulo [...] e pretendia recomeçar a vida, voltando a dar aulas particulares, realizar concertos e conferências, talvez um emprego público... O antigo discípulo, agora diretor do Serviço de Música, fez o que estava ao seu alcance: obteve imediatamente a sua admissão como professor de canto orfeônico em uma escola da capital. Atendido o pedido, Ernâni Braga não voltou a procurar Guarnieri. (Pereira, 1986, p. 77).

Em 1948, chegou notícia ao Serviço de Música da capital paulistana relacionada ao abandono daquele emprego por parte de Ernâni Braga, sem nenhuma justificativa formal por ele apresentada ao órgão público responsável

154 pela educação pública de São Paulo:

Passado algum tempo, a escola informou que o professor de canto orfeônico, abandonara as aulas por se achar enfermo. Somente então Guarnieri procurou inteirar-se do local de residência de Ernâni Braga: uma chácara, em um subúrbio da cidade. Ali não foi difícil encontrar a moradia do músico. A gente simples do lugar notara a chegada do novo morador, e tão estranha figura em um lugarejo de operários, e ainda de camponeses. $\mathrm{Na}$ casa humilde, em meio a amplo terreno, Camargo Guarnieri encontrou Ernâni Braga prostrado ao leito, sem assistência médica, enfrentando uma crise hepática aguda. Guarnieri providenciou o imediato internamento hospitalar, sendo Ernâni Braga operado de emergência, vindo a falecer. O enterro foi também providenciado pelo antigo aluno. Ernâni Braga foi enterrado com um terno de Camargo Guarnieri, tal a precária situação em que ele se encontrava. (Pereira, p. 79).

Já no artigo de Fernando Corrêa de Azevedo os últimos dias de vida de Ernâni Braga em São Paulo foram assim apresentados: 
A sua última carta é desalentadora. Tudo errado. Nenhuma situação. Barrado em toda parte. Uma longa queixa de São Paulo e das dificuldades tremendas que ali estava enfrentando. Não consegue nada. Uma oposição sistemática se levanta como uma muralha para impedir qualquer atividade sua, para impedir que penetre no meio musical daquela cidade, onde todas as portas se lhe fechavam. É quase o desespero. Tenta Belo Horizonte. Outras cidades! Tudo em vão. Ele já não cabe, como dizia, nesta pequena bola besta ou bela bosta, que é a Terra. É grato aos amigos e antigos alunos que, em São Paulo, procuram ajudá-lo e arranjar-lhe uma colocação. Mas nada conseguem. É o fim, o fim cheio de amargura, cheio de miséria, cheio de desalento, de um músico ilustre, eminente, compositor de alto nível, glória indiscutível do Brasil artístico, coração nobre, inteligência superior, cultura aprimorada, amigo dos seus amigos. Ernâni Braga pagou, até o último ceitil, a sua incorrigível boemia nesta vida. [...]

Assim era Ernâni Braga. Assim foi esse compositor brasileiro, que nos legou uma bagagem musical de primeira ordem, peças para piano, harmonizaçōes para canto de temas populares, o Quarteto Jacaré, um trio, um poema sinfônico para grande orquestra e coro, bailados, peças corais, etc. Toda a obra de Ernani Braga, infelizmente hoje dispersa, pois ele pouco se preocupou de publicá-la, revela um gosto apurado, uma elegância de tratamento, uma finura de formas, um acabamento esmerado, tudo servido por uma técnica bem ajustada e uma confecção original, que só um muito bom músico poderia produzir. Foi indiscutivelmente, além de excelente pianista, um grande compositor, que ainda há de ocupar o lugar que the compete na música brasileira. (1965, 45, 54-55).

\section{Considerações finais}

As consideraçōes finais deste artigo estão, necessariamente, ligadas à 155 ausência de estudos específicos de personalidades como Ernâni Braga e Fernando Corrêa de Azevedo: ambas possuem histórico de atividades culturais, administrativas e artísticas significativàs em suas épocas, em diversos Estados brasileiros, mas que, de maneira sistemática, vêm sendo negligenciadas pelas pesquisas acadêmicas mais recentes. Ressalta-se que, não obstante a crescente produção de áreas da Musicologia, incluindo a Histórica, ${ }^{19}$ o melhor

\footnotetext{
${ }^{19}$ Menciona-se aqui apenas e tão somente quatro trabalhos acadêmicos recentes, pioneiros na abordagem histórica relacionada a músicos atuantes no século XX, e que, de alguma maneira, serviram de referências para a elaboração do presente artigo: a) Denis Tadeu R. Vidal, $A$ produção musicológica de Clóvis de Oliveira (Dissertação - IAUUNESP, 2005); b) Fernando Menon, Jeunesses Musicales e sua representacão civil no Paraná: Juventude Musical Brasileira $8^{a}$ Região PR/SC - Setor Paraná (1953-1963) (Dissertação - UFPR, 2008); c) Maria de Fátima Estelita Barros, Waldemar Henrique: Folclore,Texto e Música num único projeto - a Canção (Dissertação - IAJUNICAMP, 2005); d) Marcos Câmara de Castro, O original evidente em Fructuoso Vianna, ECA/USP, 2007.
} 
conhecimento de personalidades como as supramencionadas, está ainda por ser melhor ampliado. ${ }^{20}$ Faz-se necessário, portanto, a maior realização de estudos e a sua conseqüente divulgação nos meios acadêmicos de pesquisa relacionada a personalidades ainda não suficientemente conhecidas do mundo musical brasileiro. No caso específico de Ernâni Braga, ficou patente a carência de pesquisas sobre a circulação/trânsito profissional de músicos brasileiros pelo País e demais unidades da América Latina, especialmente, Argentina e Uruguai.

O presente artigo integra os estudos do grupo de Pesquisa CNPq/UFPR denominado Música brasileira: estrutura e estilo, cultura e sociedade, na linha de pesquisa Musicologia histórica: entidades civis vinculadas à Música no Estado do Paraná, século XX, criado em 2004. Nas atividades desse grupo, três entidades paranaenses estão, de maneira mais intensa, servindo de temáticas de pesquisas acadêmicas, a saber: a Sociedade de Cultura Artística Brasílio Itiberê (SCAB), atuante entre 1944-1976; a Juventude Musical Brasileira - $8^{\text {a }}$ Região PR/SC (JMBPR/SC) - ambas lideradas e presididas majoritariamente por Fernando Corrêa de Azevedo - além da Sociedade Pró-Música de Curitiba (SPM-Curitiba), criada em 1963 e ativa até hoje.

A figura de Ernâni Braga, como pôde ser observado ao longo do presente texto, surgiu nas pesquisas relacionadas aos eventos de inauguração da $S C A B l$, e ao longo dos primeiros anos de atividades desta entidade cultural paranaense, entre 1945-1946. Foi, de certa maneira, um aspecto secundário da pesquisa sobre as atividades iniciais da $S C A B I$, que possibilitou a investigação mais aprofundada da vida de Ernâni Braga pelo Brasil e pela Argentina.

${ }^{20}$ Colaborou também para o esquecimento de Ernâni Braga, cujo nome completo era Ernâni da Costa Braga, a semelhança com o nome do compositor Francisco Braga, cujo nome completo era Antônio Francisco Braga. Um exemplo disso pode ser constatado no libreto do CD Tereza Berganza - mezzosoprano - Villa-Lobos, Braga, Gustavino, gravadora Claves digital, 1984, em que há o registro de canções de Ernâni Braga atribuídas a Francisco Braga. Informação disponível em: http://www.elpais.com/articulo/cultura/BRASIL/popularismo/brasileno/Ernani/Braga. Acesso em: jan. 2009. 


\section{Referências}

AZEVEDO, Fernando Corrêa de. O Ernâni Braga que eu conheci: aspectos sentimentais e humorísticos de uma grande e forte personalidade, através de sua correspondência. In: BAC, Eurico (Coord.). Humanitas, v. 7, anuário de 1964. Curitiba: Universidade Católica do Paraná, Faculdade de Filosofia, Ciências e Letras, 1965. p. 41-55.

CARLINI, Álvaro. Corais na SCABI (1945-1965). In: IV SIMPÓSIO DE PESQUISA EM MÚSICA (SIMPEMUS). Anais... Curitiba: Editora DeArtes/UFPR, 2007. p. 21-29.

PEREIRA, Gisete de Aguiar Coelho. Ernâni Braga, vida e obra. Recife: Secretaria de Educação do Estado de Pernambuco, DSE/Departamento de Cultura, 1986. 182p. il.

SAMPAIO, Marisa Ferraro. Memória-Paraná (XXII): Fernando Corrêa de Azevedo (19131975). Jornal do Comércio, Curitiba, fev. 1989.

WISNIK, José Miguel. O coro dos contrários. a música em torno da Semana de 22. 2. ed. São Paulo: Livraria Duas Cidades, 1983.

ENCICLOPÉDIA DA MÚSICA BRASILEIRA - erudita, folclórica e popular. São Paulo: Art Editora, 1977. v. I e II.

Álvaro Carlini: alvarocarliniufpr@gmail.com

Artigo recebido e aprovado em 02 de fevereiro de 2009 